\title{
СПЕЦИФИКА ВНЕШНЕПОЛИТИЧЕСКОГО КУРСА НЕОГОЛЛИСТОВ В ЛИВАНЕ И СИРИИ В 1995-2012 ГГ
}

\section{THE SPECIFICS OF THE EXTERNAL POLICY OF NEOGAULLISTS IN LEBANON AND SYRIA IN 1995-2012}

\section{A. Afonshina}

Summary: This article refers to the topic of external policy of France in the Middle East, more precisely in Lebanon and Syria, two of the important states of the region, actively involved in the regional processes and conflicts. The analysis of external policy is done from the point of view of neogaullism and the period that is studied in the article includes the presidency of Jacques Chirac and Nikolas Sarkozy, who used to stick to the political tradition of Gaullism and neogaullism. According to this tradition the external policy of France has mostly the "Arabic vector" and sticks to support Arab states mostly but at the same time neogaullists didn't manage to develop fruitful relations with Syria due to its undemocratic government. The author tries to give a full characteristic of bilateral relations between France and Lebanon as well as France and Syria mentioning their mutual dependence. This is done from basing not only on the results of the two presidencies but also on the external policy of neogaullism.

Keywords: France, bilateral relations, neogaullism, Jacque Chirac, Nicolas Sarkozy.
Афоньшина Александра Ильинична

К.и.н., преподаватель, Нижегородский Государственный Университет им. Лобачевского (г. Нижний Новгород) Aleksandra.inbox@mail.ru

Аннотация: Данная статья посвящена актуальной теме внешней политики Франции на Ближнем Востоке, а именно в Ливане и Сирии, одних из ключевых стран региона, активно участвующих в региональных процессах и конфликтах. Анализ внешней политики проводится с точки зрения неоголлизма и рассматриваемый период включает в себя придентские сроки Жака Ширака и Николя Саркози, придерживавшихся политической традиции неоголлизма, согласно которой внешняя политика Французской республики имеет преимущественно «арабский вектор развития». Автор старается дать характеристику двусторонним отношениям Франции и Ливана, а также Франции и Сирийской Арабской Республики, исходя из внешнеполитической традиции неоголлизма, а также результатов, достигнутых в конце рассматриваемого периода.

Ключевые слова: Франция, Ливан, Сирия, двусторонние отношения, Жак Ширак, Николя Саркози, неоголлизм.
Б удучи бывшей подмандатной территорией Франции, Ливан продолжал притягивать внимание французских политиков и после обретения независимости в 1943 и вывода французского контингента в 1946 году. Внешняя политика голлистов в регионе, имея преимущественно арабский вектор развития, также затрагивала и развитие отношений между Ливаном и Францией. Одним словом, эпоха президентов-голлистов была напрямую связана с расцветом французско-ливанских отношений. Что же касается французско-сирийских отношений, то можно отметить, что они также связаны с разрешением ливанских кризисов, так как Сирия также является одним из основных игроков в постоянно возникающих кризисах в Ливане.

Отношения между Францией и Ливаном не могут рассматриваться отдельно от международного контекста, учитывая, что регион Ближнего Востока всегда привлекал различных международных акторов. Выстраивая отношения с Ливаном, Франции также приходилось считаться с позицией США, оказывающих Ливану значительную военную помощь и претендующих на значительное влияние в регионе. Как заметил исследователь
В. Мансерон: «французские амбиции в арабских странах определены теми лимитами, которые устанавливают американцы: никаких инициатив в вопросах обороны, ограниченные действия в политической и экономической сферах, в той мере, чтобы американские интересы не были затронуты, карт бланш для франкофонии и в целом развитии культуры» [Manceron, 1997]. Нельзя не согласиться с такой характеристикой ситуации, так как, несмотря на значительное влияние Франции в регионе, США оставались единственной супердержавой и также были крайне заинтересованы в усилении своего влияния в регионе Ближнего Востока, особенно после развала СССР, который также имел там значительные интересы.

С приходом в Елисейский дворец Жака Ширака в 1995 г. было заявлено о возвращении Франции на Ближний Восток. Новый президент заявил о возобновлении диалога Франции с Югом, Средиземноморьем и арабским миром. Это было заявлено во время его речи в Университете Каира, а через несколько дней президент подтвердил свои намерения во время своего визита в Бейрут. Будучи неоголлистом, Жак Ширак, как и генерал 
де Голль, желал проводить независимую политику от своих трансатлантических партнеров, однако, был ограничен не только лимитированным весом Франции на международной арене, но и внутриполитической ситуацией в стране. В течение пяти из семи лет первого президентского срока Жака Ширака, президент имел так называемое правительство «сожительства», представленное социалистом Л.Жоспеном и его командой. Несмотря на то, что исторически внешняя политика является «преимущественно президентской», премьер-министр также играет важную роль в выработке внешнеполитического курса, особенно в ситуации, когда президент и премьерминистр представляют разные политические партии. Французские социалисты строят свою внешнюю политику в Ливане на поддержании сбалансированных отношений между христианским и мусульманским населением, тем самым гарантируя политическую и социальную сбалансированность политики. Кроме того, французские социалисты были близки к Прогрессивно-социалистической партии (PSP) Ливана, возглавляемой Валидом Джумблатом, одним из лидеров друзской общины. Неоголлисты, включая Жака Ширака, часто придерживались более волюнтаристского подхода, принимая во внимание теплые личные отношения между президентом Французской республики и премьер-министром Ливана Рафиком Харири. Принимая во внимание эти факторы, стоить заметить, что в первые годы президентства Жака Ширака Франция не выступала со значительными политическими инициативами.

В 1996 году Жак Ширак совершил первый визит французского президента в Ливан со времен обретения независимости страной в 1943 году. В ходе визита президент выступил перед Парламентом, заявив о независимости и суверенитете Ливана, а также призвав к выводу израильских и сирийских войск из страны [5]. Французский президент также предложил размещение французского контингента на Голланских высотах и в Южном Ливане для гарантий безопасности в случае заключения мирного договора между Израилем и Сирией. Следует заметить, что частота контактов между французской и ливанской сторонами за время президентства Жака Ширака была беспрецедентной: премьер-министр Ливана Рафик Харири совершил 14 рабочих визитов во Францию, а французский президент 4 визита в Ливан.

Отношения развивались также в экономической сфере. Побуждая бизнес-сообщество к активному развитию контактов, страны подписали в 1996 году соглашение по поощрению и взаимной защите инвестиций между Францией и Ливаном [6]. Вступив в силу в 1999 г., оно гарантировало французским инвесторам такое положение на рынке Ливана, как и национальным. Также было подписано множество финансовых межправительственных протоколов [9], облегчающих финансирование производства товаров и услуг. Следует заметить, что в 2002 году Франция стала вторым по объему торговли партнером Ливана, что, несомненно, было результатом активной деятельности в экономической области [Simon, 2006].

Говоря об экономической поддержке Ливана, нельзя не отметить, что именно президент Ширак стоял у истоков организации международных конференций, прошедших в 2001, 2002 и 2007 годах в Париже, в 2006 году в Стокгольме. Данные конференции были направлены на поддержку в «реабилитации» Ливана и на помощь правительству Р. Харири в проведении реформ. Представители ЕС, Международного валютного фонда, официальные лица Саудовской Аравии предоставили значительные кредиты правительству Ливана. Так, по итогам последней конференции в 2007 году Ливану была предоставлена международная помощь в 7,6 миллиардов долларов [Haddad, 2009].

В рамках голлистского видения внешнеполитического вектора на Ближнем Востоке, французские дипломаты обратили большее внимание на развитие отношений с мусульманским населением - суннитами и шиитами. Таким образом, французские власти старались отойти от образа «защитника маронитов», завоевывая симпатии всего ливанского общества [Clause, 2008].

Если говорить о франко-сирийских отношениях, то в течение своего первого президентского срока Жак Ширак старался улучшить довольно натянутые отношения с Сирийской Арабской Республикой. В конце 1990-х годов фигура молодого Башара Асада, который рассматривался как преемник его отца Хафеза Асада на посту президента страны, представлялась французской стороны как возможность продвинуться в решении наиболее болезненных ближневосточных вопросов, таких как: роль Сирии в арабо-израильском вопросе, потенциально-возможное влияние Сирии на политику Хамаса на палестинских территориях и, конечно же, сирийское присутствие на территории Ливана. Жак Ширак совершил два официальных визита в Сирию - один в 1996 году в ходе своего турне по Ближнему Востоку, а второй в 2002 году. В 1996 году Жак Ширак обсуждал с сирийским лидером вопросы сирийско-израильского урегулирования, признавая, что Голанские высоты являются территорией Сирии. Касательно ливанского досье французский президент лишь высказался о необходимости для ливанских властей осуществлять полный контроль над своей территорией. Стоить заметить, что Жак Ширак был единственным лидером Западного мира, присутствовавшим на похоронах Хафеза Асада в 2000 году. Елисейский дворец старался активно налаживать контакты с сирийской стороной и в частности с новым лидером Сирии Башаром Асадом. Поддержка французами сирийского режима выражалась не только в официальных визитах глав государств, но и поставках оружия в Сирию [Guitta, 
2005]. Стоит заметить, что активные франко-сирийские контакты привели к нескольким договорам о сотрудничестве в культурной и экономической областях, а в 2002 году Франция в рамках ЕС стала инициатором подписания соглашения о сотрудничестве между ЕС и Сирией, что должно было принести значительные экономические преференции для Сирии [Смирнова, Золина, 2009].

Однако, события в Ливане кардинально изменили обстановку в стране и повлияли на франко-сирийские отношения. Следует отметить, что в результате политики Хафеза Асада еще в конце 1970-х годов Сирия оккупировала часть территории Ливана и играла значительную роль во внутренней политике страны. Несмотря на ожидания изменения политики сирийского руководства с приходом нового президента, Дамаск продолжал активно вмешиваться в дела соседа и не выводил свои войска из Ливана. В 2004 году в преддверии президентских выборов в Ливане, сирийское руководство надавило на Бейрут с целью произвести изменения в Конституции страны и переизбрать действующего президента страны Эмиля Лахуда на третий срок. Что же касается Франции, то французское руководство поддерживало премьерминистра Ливана - Рафика Харири, который находился в оппозиции президенту, так как выступал против сирийского влияния на Бейрут [Perrin, 2009].

На почве данного внутриливанского конфликта сошлись интересы Парижа и Вашингтона, которые стремились к выводу сирийских войск из Ливана. В данной ситуации Франция активно занялась решением данного вопроса, став инициатором резолюции 1559 СБ ООН. Данная резолюция предусматривала территориальную целостность Ливана и призывала к выводу всех иностранных войск из страны, а также демилитаризацию всех ливанских и неливанских нерегулярных формирований [3]. Так дипломатический советник Ж. Ширака Морис Гурдол-Монтань вел переговоры по поводу данной резолюции с Кондолизой Райс, которая на тот момент занимала пост советника президента США по национальной безопасности [Ayad]. Французская дипломатия смогла убедить международное сообщество в необходимости активных действий в решении ливанского вопроса, что означало подтверждение значительной роли Франции в регионе.

Последовавшее через несколько месяцев убийство ушедшего в отставку премьер-министра, «большого друга Франции», Рафика Харири еще больше укрепило влияние Франции в ливанском вопросе, в то же самое время ухудшив франко-сирийские отношения. Президент Франции воспринял данное убийство не только как политическое убийство, но и как личную трагедию, так как с бывшим премьер-министром его связывали продолжительные теплые отношения. В результате Париж активно включился в расследование данного вопроса, убедив членов СБ в необходимости создания международного трибунала по поводу убийства Р. Харири. Сначала была создана Независимая комиссия ООН, а потом этим делом занялся Специальный трибунал в Гааге. Вновь французская дипломатия взяла на себя ведущую роль в решении ливанских вопросов.

Убийство Р. Харири и принятие резолюции 1559, направленной против сирийских войск на территории Ливана и принятой при инициативе Парижа, значительно ухудшило отношения между Сирией и Францией. Несмотря на то, что комиссия ООН не нашла прямой причастности сирийских спецслужб к убийству и Дамаск заявлял о своей готовности сотрудничать со следствием, Париж заморозил контакты с Дамаском. Одной из причин также можно назвать неоправдавшиеся ожидания Франции по поводу нового лидера Сирии. Елисейский дворец ожидал, что с приходом нового президента позиция Дамаска на международной арене изменится и в общем сирийский режим станет более демократичным. Однако, по прошествии нескольких лет Башар Асад не продемонстрировал своего желания изменять политику страны.

В последний год своего президентского мандата Жак Ширак еще раз принял активное участие в разрешении ливанских проблем. Летом 2006 года разразилась вторая ливанская война между Израилем и Хезболлой, занявшей южные районы Ливана. В самом начале войне президент Ширак предложил план по прекращению огня, включавший в себя как и гуманитарные действия, направленные на эвакуацию мирных жителей и финансовую помощь для последующего восстановления инфраструктуры, и политическое решения, предполагавшее и гарантии безопасности Израилю, и исполнение резолюции 1559. В рамках этих действий предполагался вывод Хезболлы из южного Ливана, а также размещение международного контингента (преимущественно французского [Chirac, 2006]). Основные предложения Франции были включены в резолюцию 1701 СБ ООН [4], что еще раз показало влияние Франции на события в регионе [Бородкина, 2009], к которому так стремился Ширак в начале своего президентского срока, анонсировав в Каире «возвращение Франции на Ближний Восток».

Новый президент Франции, вступивший в должность в 2007 году, в первую очередь решил начать разрешение ливанского кризиса и арабо-израильского конфликта с нормализации отношений с Сирией, которые были практически заморочены с момента убийства премьер-министра Ливана Р. Харири. Таким образом, Николя Саркози намеревался осуществить разрыв с политикой Жака Ширака в тоже время, не оставляя традиционных связей между Парижем и Бейрутом, для активизации которых предыдущая администрация приложила немало усилий.

Говоря о ливанском направлении во внешней по- 
литике Франции, можно отметить, что Николя Саркози (2007-2012 гг.) продолжал поддерживать линию Жака Ширака. В интервью ливанскому изданию в июне 2008 года, французский президент заявил о необходимости исполнять резолюцию СБ ООН 1701, о вовлечении Франции о восстановление Ливана (3 конференции спонсоров в Париже). В другом своем интервью Н. Саркози также упомянул Хезболлу, заявив, что «Хезболла является военным формированием, которая дестабилизирует государство и, очевидно, выполняет приказы Сирии и Ирана». Такая позиция была новой для французского руководства, которое на протяжении нескольких лет препятствовало внесению данной исламистской партии в список террористических организаций ЕС.

В 2008 году президент совершил официальный визит в Бейрут вместе с представителями основных политических партии Франции. Так он встретился с только что избранным президентом Ливана, которого стране удалось избрать со значительными сложностями, так как данная позиция была вакантна в течение 6 месяцев. Однако, Франция старалась не вмешиваться в данный процесс, показывая приверженность к поддержанию суверенитета Ливана, о чем Н. Саркози вновь заявил в ходе данного визита.

Экономические отношения также развивались. Так, на 2009 год Ливан оставался седьмым партнером Франции на Ближнем Востоке. Что же касается инвестиций, то, не считая арабских стран, Франция была первым инвестором в Ливан, вкладывая около 62 миллионов евро в год.

Несмотря на то, что традиционно Франция уделяла огромное внимание отношением с Ливаном, Николя Саркози с самого начала своего президентского срока налаживал отношения с Дамаском. Так, министр иностранных дел Франции несколько раз посещал Бейрут с официальным визитом, советники Елисейского дворца отправились в Дамаск, стараясь оказать давление на сирийские власти, поддерживающие оппозиционные силы в Ливане и старающиеся влиять на соседнюю странy [Cahen, 2009].

Эти переговоры принесли определенные успехи. В Ливане наметилось определенное затишье, и был избран новый президент. 12 июля 2008 году в Париже в ходе многосторонней встречи с эмиром Катара и своими ливанскими и сирийскими коллегами Николя Саркози анонсировал обмен послами между Бейрутом и Дамаском. Несомненно, данный дипломатический прорыв был значительным не только для Ливана и Сирии, но и для Франции, выступавшей посредником в данном вопросе [Déclaration de MM. Nicolas Sarkozy, 2008].

Президент Сирии также был приглашен на праздно- вание национального праздника Франции - взятия Бастилии 14 июля. Данный шаг был воспринят как желание Н. Саркози показать нормализацию отношений между двумя странами, а также, возможно, разорвать традиционные исторические связи между Тегераном и Дамаском. Следует заметить, что США достаточно скептически относились к таким действиям Парижа [Malbrunot, 2016]. Основной вопрос, который возникает в данном случае: получила ли Франция реальные преимущества от такого сотрудничества с Дамаском?

С одной стороны, усилились связи между спецслужбами Франции и Сирии, что помогло вычислить большое количество молодых джихадистов французского происхождения, направлявшихся в Ирак через Сирию [Malbrunot, 2015]. С другой стороны, Париж надеялся на определенные экономические преференции. Однако, ни проект по строительству метро в Дамаске, ни проект по реконструкции аэропорта в Дамаске не были отданы французским компаниям. И самое главное - данное сближение с Сирией не позволило Франции приблизиться к решению арабо-израильского кризиса и стать значимым посредником в данном вопросе, на что так рассчитывал Н. Саркози.

Французские власти надеялись, что постепенно режим в Сирии демократизируется, ослабит свой контроль над Ливаном и начнет конструктивный диалог по поводу мира на Ближнем Востоке. Данные неудачи на сирийском направлении были одной из причин резкого поворота внешнеполитического вектора Парижа с началом первых выступлений в Сирии. Несмотря на заявления посла из Дамаска Эрика Шевалье о том, что «режим Асада не падет, Асад силен», которые подтверждались заявлениями спецслужб, министерство иностранных дел в лице директора кабинета Эрве Ладсу и советника Николя Саркози по Ближнему Востоку Николя Галея высказывали уверенность в неминуемом падении власти Б. Асада. Н. Галей заявлял, что «Франция не намерена больше поддерживать диктатора» [Chesnot, 2014]. То же самое и подтверждал министр иностранных дел Ален Жюппе, считая, что дни Б. Асада сочтены. Поэтому весной 2011 году, французские дипломатия, не желавшая повторять ошибки, совершенные в Тунисе и Египте, решила поддержать протестующих, тем самым встав, как им казалось на тот момент, на «правильную сторону Истории». Данный кризис в Сирии показал также и кризис в процессе принятия решений в Париже. Ситуация, при которой никто не желал слушать доклады посла Франции в Сирии и доклады спецслужб, не могла привести к сбалансированному решению.

Подводя итоги развития отношений Франции с Ливаном и Сирией в течение двух президентских сроков Жака Ширака, можно отметить значительный подъем влияния Французской республики в регионе. Продол- 
жая голлистские традиции, Жак Ширак старался добиться признания Франции как значимого игрока, тем самым усилив «величие» Франции, которого исторически стараются добиться голлисты. Данная политика, безусловно, принесла свои плоды, такие как экономические преференции для Франции в Ливане, например. Однако, несмотря на возвращение статуса одного из ключевых игроков в решении ливанского вопроса и попыток наладить отношения с Сирией, политика президента-неоголлиста имела свои лимиты. Во-первых, влияние Франции и влияние США в регионе несоизмеримы. Соответственно, значительные решения (такие как резолюции СБ ООН) могут быть приняты только при заинтересованности американской стороны и ее вовлечении в проект. Будучи главным партнером Израиля в регионе, США крайне неохотно идут на какое-либо ослабление позиций еврейского государства, в то же самое время имея на Израиль огромное влияние. Во-вторых, улучшение двусторонних отношений между Францией и Сирией во многом должно было строиться на фигуре нового сирийского президента, однако, неоправданные ожидания Елисейского дворца по изменению вектора сирийской внешней политики привели лишь к краткосрочному потеплению, которое не принесло значительных политических или экономических преимуществ.

На данном направлении Н. Саркози решил изменить внешнеполитический курс предыдущей администрации, разморозив отношения с Сирией, надеясь найти путь к решению ключевых проблем в регионе через сотрудничество с Дамаском. Однако, сирийское руководство не было настроено изменять свою политику как в регионе, так и внутри страны. Более того, следует отметить тот факт, что Дамаск также осознавал, что ключ от решения арабо-израильского конфликта находится не в Париже, а в Вашингтоне, и что Франция имеет крайне ограниченное влияние на Израиль. Ливано-французские отношения продолжали развиваться в векторе, заданном предыдущей администрацией, хотя ливанское руководство крайне настороженно относилось к контактам Парижа и Дамаска. Если расценивать внешнеполитический курс Николя Саркози в регионе с точки зрения неоголлизма, здесь можно отметить, что в политике президента, несомненно, присутствовала идея «величия» Франции и желания продемонстрировать активную роль Парижа в решении региональных проблем. Однако, просчеты внешней политики в Тунисе и Египте во время начала антиправительственных выступлений в этих странах, не позволили французскому руководству правильно и самостоятельно оценить внутриполитическую ситуацию в Сирии. Таким образом, Франция поддержала точку зрения США, выступив на стороне протестующих, не принимая во внимание мнение некоторых дипломатов. В итоге, Париж не смог занять самостоятельной позиции по данному вопросу, а точка зрения Вашингтона насчет скоро свержения режима Б. Асада оказалась неверной.

\section{ЛИТЕРАТУРА}

1. Бородкина, Н.В. Роль Ливана в Ближневосточной политике Франции при президенте Ж. Шираке / Н.В. Бородкина // Вестник Северного (Арктического) федерального университета. Серия: Гуманитарные и социальные науки. - 2009. - №. 6, с. 7-9.

2. Смирнова 0.А., Золина Д.М. Эволюция взаимоотношений французской республики с государствами Ближнего Востока (Сирия, Ливан) / 0.А. Смирнова, Д.М. Золина // Вестник Волгоградского государственного университета. Серия 4: История. Регионоведение. Международные отношения. - 2009. - №. 1(15), c. 163-168

3. Резолюция 1559 (2004), принятая Советом Безопасности на его 5028-м заседании 2 сентября 2004 года [Электронный ресурс] // 00Н. - Режим доступа: https://documents-dds-ny.un.org/doc/UNDOC/GEN/N04/498/94/PDF/N0449894.pdf?OpenElement (дата обращения: 21.05.2021)

4. Резолюция 1701 (2006), принятая Советом Безопасности на его 5511-м заседании 11 августа 2006 года [Электронный ресурс] // 00Н. - Режим доступа: https://documents-dds-ny.un.org/doc/UNDOC/GEN/N06/465/05/PDF/N0646505.pdf?0penElement (дата обращения: 21.05.2021).

5. 4-8 avril 1996 France - Liban - Égypte. Visite officielle du président Jacques Chirac à Beyrouth et au Caire [Electronic resource] // Encyclopadia Universalis. - Mode of access: https://www.universalis.fr/evenement/4-8-avril-1996-france-liban-egypte-visite-officielle-du-president-jacques-chirac-a-beyrouth-et-au-caire/ (date of access: 21.05 .2021$)$

6. 28 novembre 1996: Accord sur l'encouragement et la protection réciproques des investissements [Electronic resource] // France-États arabes. - Mode of access: http://fothman.free.fr/Accbitxt/Eco/lb_eco/lbeco281196/lbeco281196.html (date of access: 21.05.2021)

7. Ayad, C. Quand la Syrie monte au nez de Chirac [Electronic resource] / C. Ayad [et al.] // Liberation. - Mode of access: http://www.liberation.fr/grandangle/2005/03/22/quand-la-syrie-monte-au-nez-de-chirac_513761 (date of access: 21.05.2021).

8. Cahen, J. La politique syrienne de la France, de Jacques Chirac à Nicolas Sarkozy / J. Cahen // Politique étrangère. - 2009. - № 1, p. 177-188

9. Contenu des accords franco-libanais [Electronic resource] // France-États arabes. - Mode of access: http://fothman.free.fr/ParPays/bi_lb.html (date of access: 25.06.18)

10. Claude, G. Les relations franco-libanaises sous la présidence de Jacques Chirac / G. Claude // Politique étrangère. - 2008. - № 4, p. 885-889

11. Chesnot, C. Les chemins de Damas: le dossier noir de la relation franco-syrienne / C. Chesnot, G. Malbrunot. - Robert Laffont, 2014.

12. Déclaration conjointe de MM. Nicolas Sarkozy, Président de la République, Cheikh Hamad Bin Khalifa Al-Thani, émir de l'Etat du Qatar, Bachar Al-Assad, Président de la République arabe syrienne, et Michel Sleimane, Président de la République libanaise, sur la situation politique au Liban, le processus de paix entre Israël 
et la Syrie et sur la question palestinienne, à Paris le 12 juillet 2008 [Electronic resource] // Vie-publique. - Mode of access: http://discours.vie-publique.fr/ notices/087002334.html (date of access: 21.05.2021).

13. Guitta, 0. The Chirac doctrine / 0. Guitta // Middle East Quarterly. - 2005. - Vol. 12, № 4, p.43-55

14. Entretien de M. Nicolas Sarkozy, Président de la République, dans les quotidiens libanais "L'Orient le jour", "Annahar" et "Assafir" du 7 juin 2008 , sur les relations franco-libanaise et franco-syrienne dans le contexte de la crise politique au Liban [Electronic resource] // Vie-publique. - Mode of access: http://discours.viepublique.fr/notices/087001864.html (date of access 21.05.2021).

15. Haddad, S. France-Liban-Syrie / S. Haddad // Outre-Terre. - 2009. - № 3(23), p. 173-178

16. Intervention télévisée de M. Jacques Chirac, Président de la République, sur l'action de la France au Proche-Orient, notamment sa participation au renforcement de la Force d'intervention des Nations Unies au Liban (FINUL), à Paris le 24 août 2006 [Electronic resource] // Vie-publique. - Mode of access: http://discours.viepublique.fr/notices/067002972.html (date of access: 21.05.2021)

17. Manceron, V. La nouvelle politique arabe de Jacques Chirac ou l'art du paradoxe / V. Manceron // Revue internationale et stratégique. - 1997. - № 2. - P. 5

18. Malbrunot, G. Contradictions françaises au Moyen-Orien / G. Malbrunot // Politique étrangère, - 2016. - № 2, p. 75-85

19. Malbrunot, G. La France face au conflit syrien: le choix de l'i-realpolitik / G. Malbrunot // Outre-Terre. - 2015. - № 3(44), p. 23-26.

20. Simon, N. Rags to Riches, and Back? / N. Simon // The Jerusalem Report. - 21 août 2006, p. 26-28.

21. Perrin, J.-P. Liban: quand Damas va trop loin / J.-P. Perrin // Politique internationale. - 2005. - № 106. - P. 41-43

(c) Афоньшина Александра Ильинична (Aleksandra.inbox@mail.ru).

Журнал «Современная наука: актуальные проблемы теории и практики»

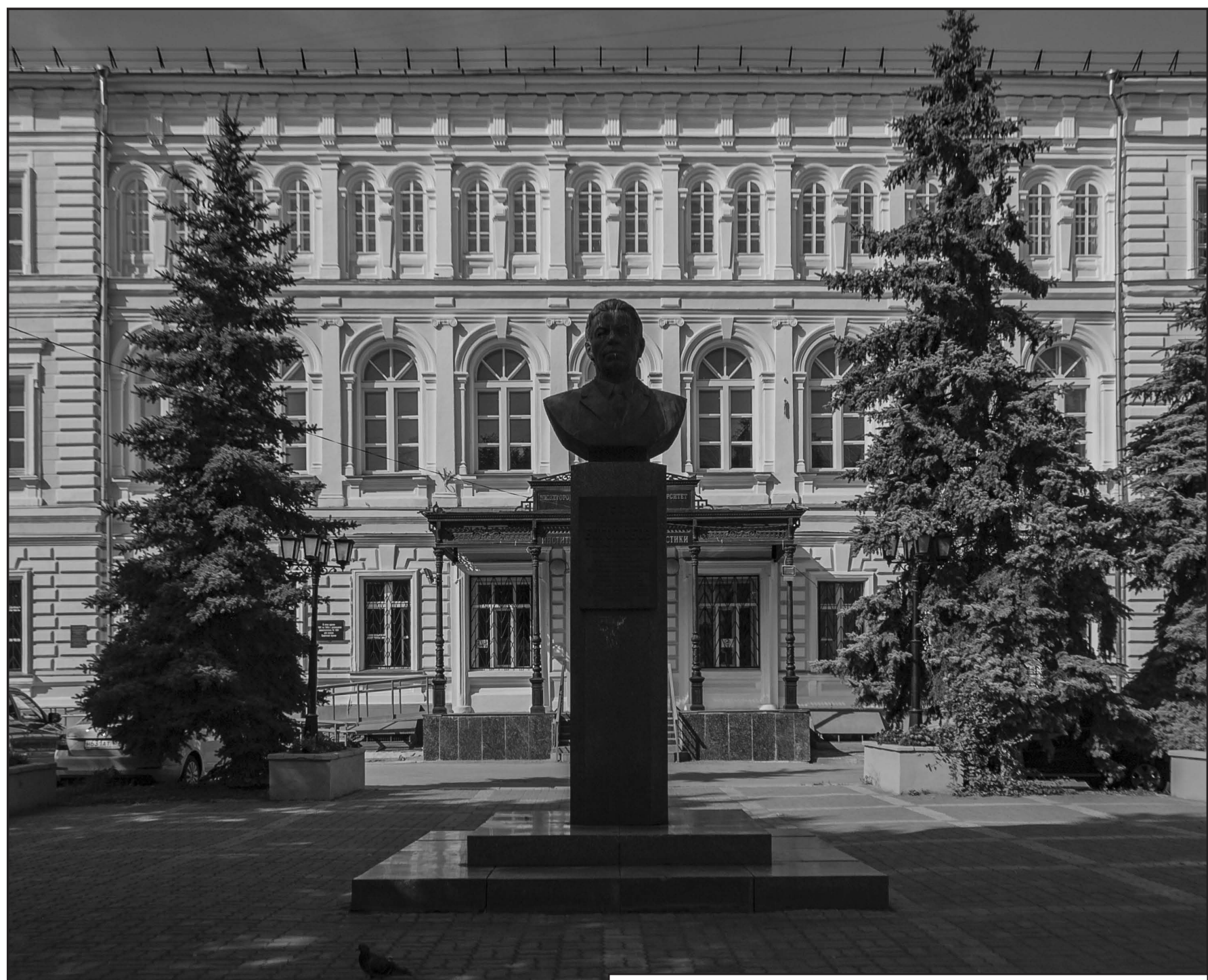

Нижегородский Государственный Университет им. Н.И. Лобачевского 